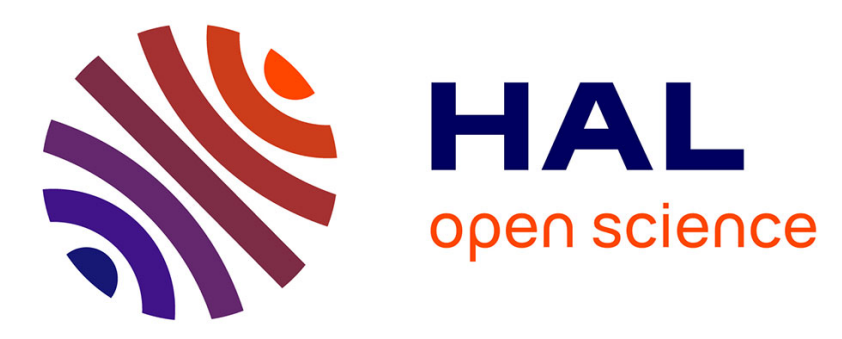

\title{
Chemical bonding and stability of multilayer graphene oxide layers
}

\author{
Cheng Gong, Suenne Kim, Si Zhou, Yike Hu, Muge Acik, Walt A de Heer, \\ Claire Berger, Angelo Bongiorno, Elisa Riedo, Yves J Chabal
}

\section{To cite this version:}

Cheng Gong, Suenne Kim, Si Zhou, Yike Hu, Muge Acik, et al.. Chemical bonding and stability of multilayer graphene oxide layers. Proceedings of SPIE, the International Society for Optical Engineering, 2014, Oxide-based Materials and Devices V, 8987, pp.89872C. 10.1117/12.2045554 . hal-01784085

\section{HAL Id: hal-01784085 \\ https://hal.science/hal-01784085}

Submitted on 3 May 2018

HAL is a multi-disciplinary open access archive for the deposit and dissemination of scientific research documents, whether they are published or not. The documents may come from teaching and research institutions in France or abroad, or from public or private research centers.
L'archive ouverte pluridisciplinaire HAL, est destinée au dépôt et à la diffusion de documents scientifiques de niveau recherche, publiés ou non, émanant des établissements d'enseignement et de recherche français ou étrangers, des laboratoires publics ou privés. 


\title{
Chemical bonding and stability of multilayer graphene oxide layers
} Cheng Gong, ${ }^{1}$ Suenne Kim ${ }^{2}$, Si Zhou ${ }^{3}$, Yike Hu${ }^{2}$, Muge Acik ${ }^{1}$, Walt de Heer ${ }^{2}$, Claire Berger ${ }^{2}$, Angelo Bongiorno ${ }^{3}$, Elisa Riedo ${ }^{2}$, and Yves Chabal ${ }^{1}$

${ }^{1}$ Department of Materials Science and Engineering, The University of Texas at Dallas, $800 \mathrm{~W}$. Campbell Rd, Richardson, Texas (USA) 75080-3021; ${ }^{2}$ Schools of Physics, Georgia Institute of Technology, Atlanta, Georgia (USA) 30332-0430; ${ }^{3}$ School of Chemistry and Biochemistry, Georgia Institute of Technology, Atlanta, Georgia (USA) 30332-0400

\begin{abstract}
The chemistry of graphene oxide (GO) and its response to external stimuli such as temperature and light are not well understood and only approximately controlled. This understanding is however crucial to enable future applications of the material that typically are subject to environmental conditions. The nature of the initial GO is also highly dependent on the preparation and the form of the initial carbon material. Here, we consider both standard GO made from oxidizing graphite and layered GO made from oxidizing epitaxial graphene on $\mathrm{SiC}$, and examine their evolution under different stimuli. The effect of the solvent on the thermal evolution of standard GO in vacuum is first investigated. In situ infrared absorption measurements clearly show that the nature of the last solvent in contact with GO prior to deposition on a substrate for vacuum annealing studies substantially affect the chemical evolution of the material as GO is reduced. Second, the stability of GO derived from epitaxial graphene (on $\mathrm{SiC}$ ) is examined as a function of time. We show that hydrogen, in the form of $\mathrm{CH}$, is present after the Hummers process, and that hydrogen favors the reduction of epoxide groups and the formation of water molecules. Importantly, this transformation can take place at room temperature, albeit slowly ( one month). Finally, the chemical interaction (e.g. bonding) between GO layers in multilayer samples is examined with diffraction (XRD) methods, spectroscopic (IR, XPS, Raman) techniques, imaging (APF) and first principles modeling.
\end{abstract}

Keywords: graphene oxide, chemical stability and evolution, infrared spectroscopy, first principles calculations

\section{INTRODUCTION}

Graphene Oxide (GO) has been considered for a number of applications involving tunable opto-electronic properties through reduction in the form of thin films ${ }^{1}$ or as a bulk powder material ${ }^{2}$ for high capacity chemical storage applications ${ }^{3}$. Graphite oxide is synthesized by strong acid/base treatments ${ }^{4-6}$ of graphite resulting in the incorporation of oxygen in many forms, such as out of plane epoxide and hydroxyl species, edge functionalization (carboxyls, carbonyls, hydroxyls) and in-plane structures (ether-like species) ${ }^{7}$, and can be further exfoliated into separate GO sheets $^{8-10}$. GO is a non-stoichiometric ${ }^{11}$, highly hygroscopic compound that is initially electrically insulating. Furthermore, GO is inhomogeneous, even within the same solution, leading to difficulties for comparisons without in situ characterization. ${ }^{12}$ While some electronic applications with graphene oxide need a conductive material (i.e. closer to graphene), some energy storage applications have additional requirements, such as contact with electrolytes.

Theoretical and experimental studies have focused on understanding the structure and chemistry of single layer GO, both in as-synthesized ${ }^{13}$ and reduced forms ${ }^{14}$ as well as the evolution of structure at different degrees of reduction ${ }^{15,16}$. Thermal reduction of GO for instance has been shown to involve the removal of epoxide and hydroxyl groups by formation of $\mathrm{H}_{2} \mathrm{O}, \mathrm{H}_{2}, \mathrm{O}_{2}$ (oxygen elimination), and also $\mathrm{CO}$ and $\mathrm{CO}_{2}$ (carbon elimination) thus creating defects in the form of etch holes within the graphene basal plane ${ }^{17,18}$. There is however little understanding of the behavior of multiple GO sheets that are stacked together in the form of thin films or as bulk materials for various energy applications ${ }^{19}$. The interactions along the $\mathrm{c}$-axis perpendicular to the GO sheets in the multilayered material have been 
mostly ignored. The multilayered structure assembled from exfoliated GO sheets is different from that of graphite oxide in that there is little or no commensurate stacking amongst the layers ${ }^{20}$. Thus interactions amongst layers in multi-layered GO are not strictly defined by the $\pi$ - $\pi$ - interactions as in graphite but are dominated by hydrogen bonding of functional groups and trapped molecules between the layers ${ }^{21}$.

For instance, the presence of water and strong interactions between GO planes have been recognized as important ${ }^{3}$, but little is known about the nature and role of water and other molecules trapped within the $\sim 1 \mathrm{~nm}^{22,23}$ spacing between the sheets at the interface, and the chemistry it can foster especially during the reduction process. Yet, control of 3D multilayered GO structures is important for a number of applications, including electrolytes within super- and hybridcapacitors $^{24}$ and batteries (ionic transport) ${ }^{25}$, mechanical actuators ${ }^{26}$ that convert external stimuli such as thermal, light, electrical $^{27,28}$, or chemical energy to mechanical energy ${ }^{29}$. In electromechanical resonators for example, the actuation depends on variation of humidity and/or temperature ${ }^{30}$. In supercapacitors, the ion transport is controlled by the size of openings (i.e. holes in GO layers) as well as the intersheet spacing ${ }^{31}$. The mechanical properties of GO paper-like composites are controlled by network of hydrogen bonds, the concentration of which can vary with water content $t^{32}$. It is clearly of fundamental importance to understand the chemistry of water confined between the sheets in pristine GO as well as reduced GO.

Several other molecules play an important role as intercalant. In energy storage devices (e.g., Li-ion batteries or ultracapacitors) ${ }^{33}$ electrolytes are used to provide electrical communication between the high surface area, chargestoring electrodes. For instance, Ionic liquids (ILs) are attractive choices for this role because of their unique and valuable physical properties (e.g., low vapor pressure, high thermal stability, non-flammability, high ion conductivity, wide electrochemical window, and low melting temperature) ${ }^{34}$ In graphene-based ultracapacitors, electrodes are commonly prepared from modified graphite or graphene. ${ }^{3}$ Once ILs are combined with the electrodes, the two components interact through Coulombic or charge polarization interactions, van der Waals, hydrogen bonding and cation- $\pi$ or $\pi-\pi$ forces, which control their wetting of the electrode and internal order. The ILs' structure and properties, such as dispersibility on the carbon and stabilization of charge buildup, determine the overall performance of the ultracapacitor. Beyond enhancing the energy storage capability of the carbon material, a proper match in surface tension of ILs and graphite also facilitates the interaction of these two components and promotes the intercalation and exfoliation of the individual graphene layers. ${ }^{35}$

Here, we review the essential findings of the role of water and other molecules in the evolution of GO during thermal annealing.

\section{WATER INTERCALATION}

Infrared absorbance spectra of typical multilayered GO (three and multi layers) thin films in transmission have been able to identify several distinct vibrational modes of various types of oxygen functionalities, such as epoxides (C-O-C, $1280-1320 \mathrm{~cm}^{-1}$ and $\sim 850 \mathrm{~cm}^{-1}$ ), edge carboxyl groups (COOH, $1650-1750 \mathrm{~cm}^{-1}$ with C-OH modes at $\sim 3000-3700 \mathrm{~cm}^{-}$ ${ }^{1}$ ), carbonyls $\left(\mathrm{C}=\mathrm{O}\right.$ and $\mathrm{O}-\mathrm{C}=\mathrm{O}, 1750-1850 \mathrm{~cm}^{-1}$ and $1500-1750 \mathrm{~cm}^{-1}$, respectively), basal plane hydroxyls and phenols (edge hydroxyls $)^{36}\left(\mathrm{C}-\mathrm{OH}, 3000-3700 \mathrm{~cm}^{-1}\right)$ and asymmetric vibrational stretching of $\mathrm{sp}^{2}$-hybridized $\mathrm{C}=\mathrm{C}(1500-1600$ $\mathrm{cm}^{-1}$ ). Although these oxygen functionalities are common to all multilayered and single-layer GO films, the absolute and relative intensities depend on both the amount of material on the substrate and the details of the preparation. Furthermore, various ketone and ester carbonyls are initially present, with spectral contributions that overlap in the most important spectral regions $\left(900-1500 \mathrm{~cm}^{-1}\right)$, greatly complicating assignments. ${ }^{37}$

The presence of physisorbed water $^{38}$ is observed even on single layer GO (GO-1L) surfaces, as evidenced by both $\mathrm{OH}$ stretching $\left(\sim 3000-3500 \mathrm{~cm}^{-1}\right)$ and scissor $\left(1600-1650 \mathrm{~cm}^{-1}\right)$ modes of $\mathrm{H}_{2} \mathrm{O}$ that are broadened through hydrogen interactions with $\mathrm{C}-\mathrm{OH}\left(\mathrm{O}-\mathrm{H}\right.$ stretch at $\left.3000-3700 \mathrm{~cm}^{-1}\right)$ and $\mathrm{COOH}\left(\mathrm{OH}\right.$ stretch at $\left.\sim 3549 \mathrm{~cm}^{-1}\right)$. These modes are markedly stronger and broader in multilayered GO (GO-ML) due to trapped water in interlayer nano-spacings ${ }^{39}$, as a result of a high hydroxyl concentration as well as stronger hydrogen bonding interactions between $\mathrm{OH}$ and other oxygen functionalities in close proximity. 
The presence of water was shown to dramatically influence the chemistry of multilayered GO upon mild heating (60$250^{\circ} \mathrm{C}$ ), typically observed by examining difference spectra of single- and multi-layer GO in the $1100-1850 \mathrm{~cm}^{-1}$ spectral region. Although the initial spectra were similar, the relative increase in intensity of the $1100-1500 \mathrm{~cm}^{-1}$ region was much higher for three- or multilayered $\mathrm{GO}$ (as the sample is annealed to $175^{\circ} \mathrm{C}$ ). Importantly, this intensity increase occurred at lower temperatures in multilayered GO $\left(\sim 125^{\circ} \mathrm{C}\right)$ than for GO-1L $\left(\sim 150^{\circ} \mathrm{C}\right)$. These observations were used to determine that, for a given number of oxygen functionalities, a larger relative concentration of ketone and ester carbonyl derivatives $\left(\sim 1500-1850 \mathrm{~cm}^{-1}\right)$ is produced in GO-ML than on GO-1L. Correlated with these observations was an intensity loss of $\mathrm{OH}$ related vibrational modes.

Fig. 1 quantifies the findings described above by showing the dependence of the integrated intensities of the $\mathrm{H}_{2} \mathrm{O}$ and $\mathrm{OH}(\mathrm{C}-\mathrm{OH}, \mathrm{COOH})$ stretching modes $\left(\sim 3000-3700 \mathrm{~cm}^{-1}\right)$ in Fig. 1i and the normalized concentration of carbonyls $\left(1100-1850 \mathrm{~cm}^{-1}\right)$ as a function of annealing temperatures in Fig. 1ii. Fig. 1i highlights the fact that a substantial amount of water is trapped between layers of multilayered GO and that there is a precipitous drop in water concentration at $\sim 150{ }^{\circ} \mathrm{C}$. In contrast, single layer $\mathrm{GO}$ is characterized by $\mathrm{OH}$ stretch region primarily arising from carboxyls and hydroxyls with relatively insignificant contribution from physisorbed $\mathrm{H}_{2} \mathrm{O}$. Consequently, there is no sharp loss of $\mathrm{OH}$ stretch intensity at $\sim 150^{\circ} \mathrm{C}$ in GO-1L.

In Fig. 1ii, the integrated area associated with carbonyl formation is normalized to the total area of all oxygen functionalities prior to annealing. While there are marked variations in dipole moments, using this overall integrated area provides an excellent average measure of the total number of oxygen present in the sample and avoids uncertainties related to uncertainties of surface coverage. The results clearly show that 1$)$ the formation of carbonyls starts at lower temperatures $\left(\sim 125^{\circ} \mathrm{C}\right)$ in three- or multilayered GO than in single layer GO $\left(\sim 150{ }^{\circ} \mathrm{C}\right)$, and 2$)$ the amount of carbonyl formed is $\sim 4$ times larger, for an identical initial oxygen concentration (in all the functional forms), for GO-3L than for GO-1L ( $110 \%$ increase instead of $\sim 30 \%$ shown in Fig. 1ii). Confirmation of a higher carbonyl formation during annealing of multilayered than single-layer GO was provided by XPS measurements.

The role of confined water in altering the chemistry of multilayered GO upon mild annealing were further elucidated by focusing on the mechanisms of carbonyl formation at $\sim 125^{\circ} \mathrm{C}$, which is accompanied by the evolution of $\mathrm{CO}_{2}{ }^{40}$ The detection of $\mathrm{CO}_{2}$ molecules indicates the formation of defects in the graphene basal plane. Such defects occur in the form of holes and have been predicted by MD simulations ${ }^{41}$ and observed by high-resolution transmission electron microscopy ${ }^{42}$. The mechanism for void formation by $\mathrm{CO}_{2}$ production is therefore believed to be based on the reaction of dissociative oxygen (from gas or water phase) with oxygen-functionalized basal plane sites and possibly epoxide migration to edges ${ }^{43}$. It has also been proposed that carbon-carbon bonds below an epoxy group can relax when aligned one dimensionally ${ }^{44}$, resulting in the introduction of cracks upon reduction ${ }^{45}$. Simultaneous decomposition of epoxides with carbonyl formation during annealing indicates that one source of basal plane defects is the epoxide removal (ring opening), similar to the case of fullerenes via nucleophilic attack ${ }^{46}$ but can also exist intrinsic upon oxidation $^{47}$. In all proposed mechanisms, the presence of water molecules in close proximity to the reactants is essential for facilitating the reaction.

To explain the large formation of these carbonyl species at $\sim 175^{\circ} \mathrm{C}$, DFT calculations have been performed using a defective GO model with a localized etch hole formed by removing at least three adjacent $\mathrm{C}$ atoms. This model etch hole is used to calculate how $\mathrm{H}_{2} \mathrm{O}$ molecules can react with one or more dangling bonds, created via $\mathrm{CO}_{2}$ production during the hole formation. While several possible reaction paths are possible with different products, calculations of the formation energy associated with each reaction indicates that there are several paths for carbonyl formation, and another with release of a $\mathrm{H}_{2}$ (exothermic by $1.0 \mathrm{eV}$ ), another involving the reaction of a hydroxyl and $\mathrm{C}-\mathrm{H}$ formation at two carbon dangling bonds with a water molecule (barrierless with an energy gain of $3.9 \mathrm{eV}$ ). These carbonyl groups subsequently react with residual epoxide groups which would migrate towards the etch hole, and such reactions will remove the carbonyl groups in the form of $\mathrm{CO}_{2} \cdot{ }^{43}$ Small activation barriers $(0.1 \mathrm{eV}$ and $0.129 \mathrm{eV})$ in Fig. 4ii (a-e) also confirm that hydroxyls and carbonyls are easily reversible at the etch holes. The fact that $\mathrm{OH}$ and $\mathrm{C}=\mathrm{O}$ formation ener- 

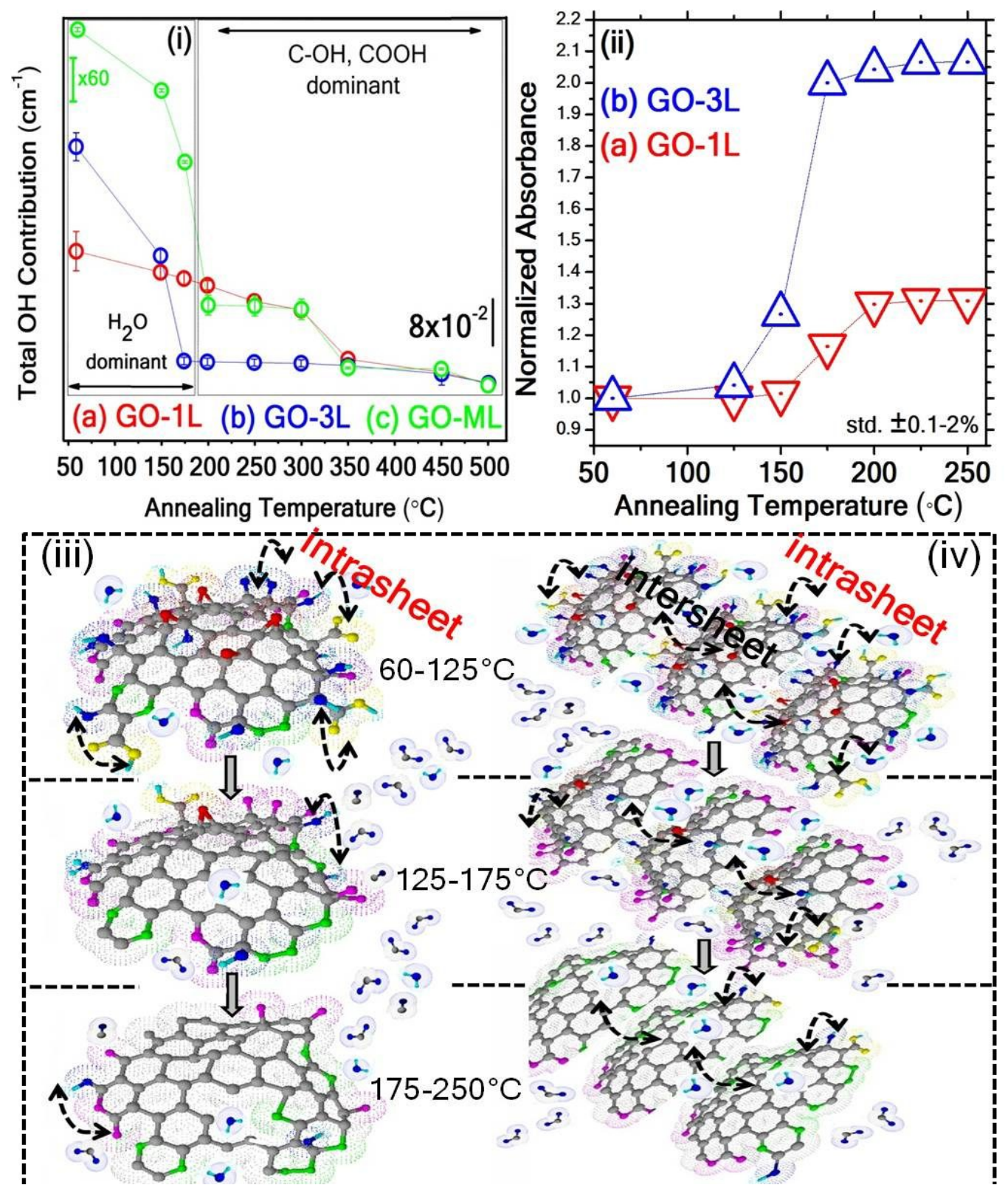

Figure 1. Comparison of the integrated total $\mathrm{OH}$ contribution from (i) $\mathrm{H}_{2} \mathrm{O}, \mathrm{OH}$ and $\mathrm{COOH}$ and (ii) normalized absorbance of integrated carbonyl concentration. (i) Integrated intensities (3000-3700 $\mathrm{cm}^{-1}$, std. $\left.\pm 0.01-0.2 \%\right)$ of C-OH peak are shown as a function of temperature for GO-1L (red), GO-3L (blue) and GO-ML (green). Removal of $\mathrm{H}_{2} \mathrm{O}$ up to $175^{\circ} \mathrm{C}$ significantly decreases the intensity of the $\mathrm{C}-\mathrm{OH}$ peak (left). After removal of $\mathrm{H}_{2} \mathrm{O}$, the intensities of $\mathrm{C}-\mathrm{OH}$ and $\mathrm{COOH}$ groups are dominant (right). (ii) Comparison of the normalized carbonyl integrated infrared absorbance (1100$1850 \mathrm{~cm}^{-1}$, std. $\pm 0.1-2 \%$ ) for both GO-1L (blue) and GO-3L (red) indicates an $\sim 110 \%$ increase instead of $\sim 30 \%$ as a function of temperature. Normalization performed by dividing to initial (prior to annealing) integrated absorbance values of $0.95 \mathrm{~cm}^{-1}$ for GO-1L and $1.54 \mathrm{~cm}^{-1}$ for GO-3L $\left(1100-1850 \mathrm{~cm}^{-1}\right)$. Model structures shown for processes involving (iii) only edge intrasheet (GO-1L) and (iv) both intra- and inter-sheet (GO-3L) interactions for $60-125^{\circ} \mathrm{C}, 125-175^{\circ} \mathrm{C}$ and 175 $250^{\circ} \mathrm{C}$. 
gies are the same indicates that these reactions are reversible and consistent with the commonly known keto-enol tautomerism $^{39}$. The incorporation of an oxygen in the basal plane through the $\mathrm{C}-\mathrm{O}-\mathrm{C}$ bond formation at two carbon dangling bond sites (resulting in cyclic ether formation along with a release of $\mathrm{H}_{2}$ ) is also energetically favorable with a formation energy of $3.0 \mathrm{eV}$. The reaction energy calculations also show that a cyclic ether and a carbonyl can form in an etch hole when two $\mathrm{H}_{2} \mathrm{O}$ molecules react with two carbon dangling bonds releasing two $\mathrm{H}_{2}$ and the formation energy $(3.8 \mathrm{eV})$ is reduced from the sum $(1.0 \mathrm{eV}+3.0 \mathrm{eV})$ due to the repulsive coulomb interaction between the oxygen atoms.

These findings and interpretation suggest that the nature of the solvent in GO could dramatically alter the subsequent chemical evolution of GO upon annealing or any other processing. Therefore, in order to verify the role of water chemistry and the mechanism of ketone and ester carbonyl formation in multilayered GO and to uncover the effect of other molecules, water was initially displaced by alcohol, as summarized in the next section.

\section{ALCOHOL INTERCALATION}

Ethyl alcohol was first intercalated by immersion at room temperature for four days, leading to an increase of interlayer spacing measured with XRD and evidence for a weakening of $\mathrm{H}$-bonding as a result of $\mathrm{H}$-bond distortion once ethyl alcohol is introduced. Differential IR spectra revealed that there is no carbonyl formation in ethyl alcohol, in contrast to the strong increase in $\mathrm{C}=\mathrm{O}$ concentration in water upon annealing. The reduction of etch hole formation is a direct consequence of the inactivity of intercalated alcohol with the graphene network. ${ }^{37}$ The intercalation of alcohol therefore confirms the critical role played by water and suggests that potential healing of defect hole is possible.

This interesting hypothesis was explored by combining density functional theory (DFT), ab initio molecular dynamics (MD) calculations and in situ infrared absorption spectroscopy, to explore the thermal evolution of both carbonyl and ether groups in multilayered GO upon individual intercalation of methanol, ethanol, and water molecules. ${ }^{48}$ While bare etch holes are generated by thermal annealing in the presence of water, as evidenced by the evolution of carbon dioxide $\left(\mathrm{CO}_{2}\right)$ molecules, the replacement of water by methanol or ethanol prevents defect formation during annealing. Furthermore, ethanol is found to repair the etch holes by facilitating the formation of new hexagonal carbon rings. $A b$ initio MD simulations map out the likely reaction pathways that are subsequently verified by DFT total energy calculations, as illustrated in Figure $2 .^{48}$ The elucidation of the mechanism of etch hole healing in GO suggests a new way to tailor the structural and electronic properties of reduced $\mathrm{GO}(\mathrm{rGO})$ and graphene for a variety of applications requiring defect engineering.

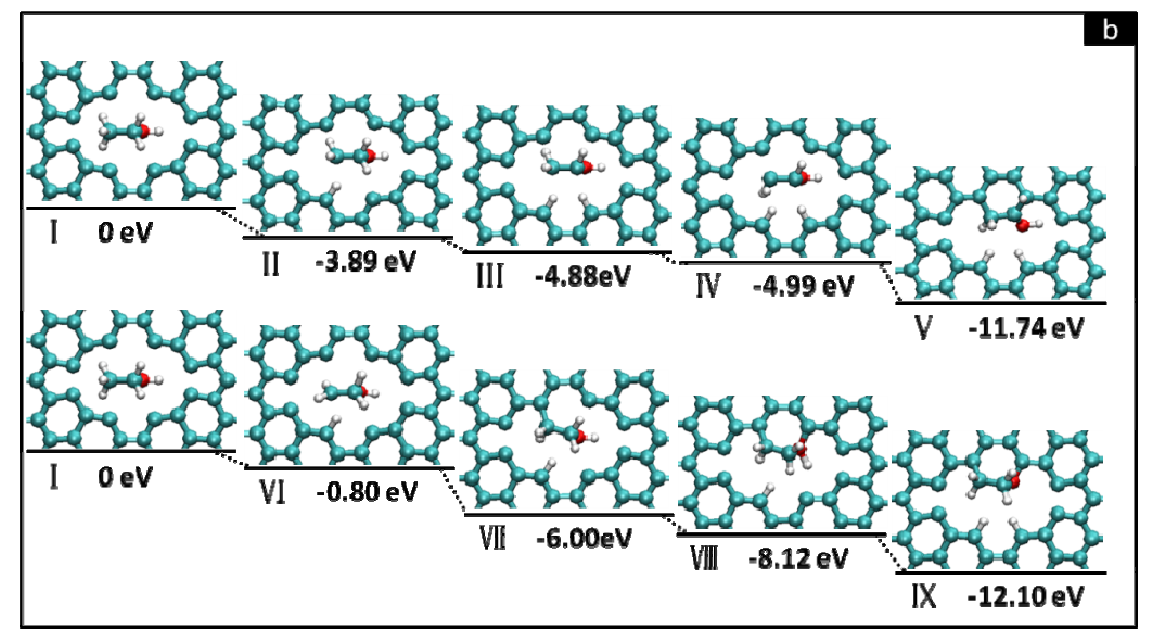

Figure 2: Reaction pathways for ethanol in a bare etch hole, where black dashed lines indicate a direct reaction without barriers. The black dashed curves in III-IV represent an adjustment of structures (e.g. rotation of fragments). 


\section{IONIC LIQUID INTERCALATION}

For energy applications, such a ultracapacitors, the intercalation of ionic liquids (ILs) become important, and understanding their interaction during processing (e.g. mild annealing to reduce GO) is necessary to make progress. For instance, the fabrication of high performance, graphene-based electrochemical ultracapacitors, depends on the reduction of graphite oxide (GO) and its interaction with ionic liquids (ILs), used as the conductive electrolyte. Since ILs are composed of an anion and a cation, the situation is more complex as the interaction of each component can play a role.

To explore the ILs' physical and chemical interactions with thermally reduced GO (TRG) as a function of annealing temperature, three ILs with ammonium core structures were selected to differentiate the role of their anions and cations in exfoliation, as illustrated in Figure 3 (1-3). ${ }^{49}$ Intercalation was accompanied by either covalent or noncovalent bonding, as determined by thermogravimetric analysis (TGA) and infrared (IR) absorption spectroscopy performed in situ during thermal annealing and by X-ray diffraction (XRD) analysis, and the results are summarized on the right side of each structure in Fig. 3.

(a)
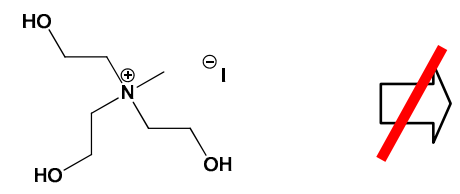

- No functionalization till $200^{\circ} \mathrm{C}$

- Partial functionalization at $250^{\circ} \mathrm{C}$

- Efficient oxygen removal

- Exfoliates with weak expansion

1

(b)

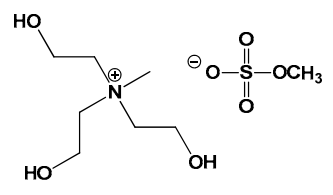

2

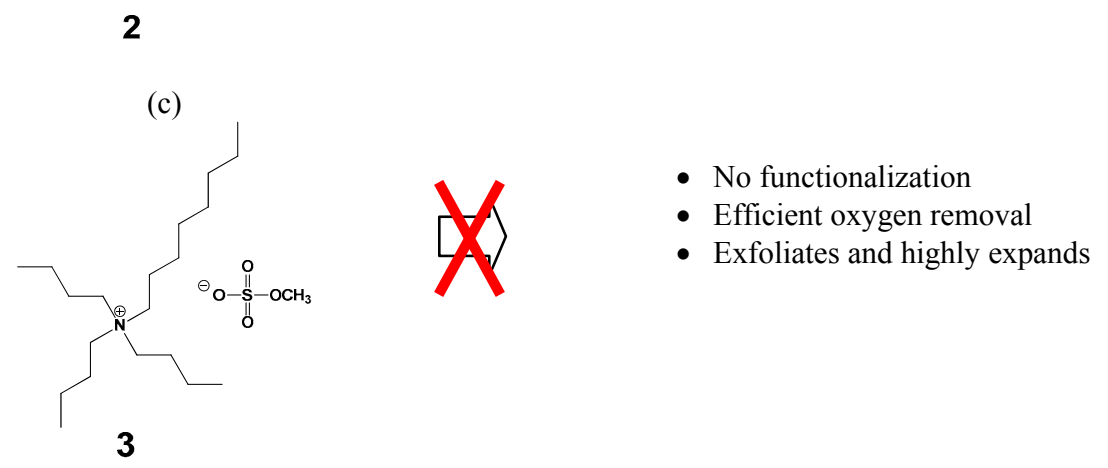

- Covalent functionalization

- Oxygen remains at $500^{\circ} \mathrm{C}$

- Exfoliates with weak

- expansion

Figure 3. (a) N-methyl-N,N,N-tris(2-hydroxyethyl)ammonium iodide (1), (b) N-methyl-N,N,N-tris(2-hydroxyethyl) ammonium methyl sulfate (2), (c) N,N,N-tributyl-N-octylammonium methyl sulfate (3), and (right) the diagnostic properties of the GIICs formed when the ILs were blended and annealed with TRG. Red bars indicate degree of non functionalization. 
Upon IL intercalation, covalent bonding between the IL and TRG was found to prevent exfoliation, while noncovalently physisorbed ILs were readily removed and therefore facilitated exfoliation of the reduced GO. The anion and cation moieties of the ILs investigated were found to influence the decomposition temperature and the degree of thermal stabilization of the TRG-IL composites. Indeed, cations bearing long alkyl chains did not functionalize the TRG and therefore promoted both sheet expansion and exfoliation. The solvent-dependency of these properties was also investigated by forming GO-IL intercalation compounds (GIICs) from both deionized (DI) water and propylene carbonate (PC).

Specifically, both the anion and cation moieties of ILs intercalated into GO were found to influence the degree of expansion and exfoliation upon thermal annealing of GIICs. The intercalated ILs were capable of modulating the $\mathrm{T}_{\mathrm{d}}$ of the TRG-IL composites, which facilitated the stabilization of the IL in the TRG interlayer spacing. Cations bearing long, unfunctionalized alkyl chains stabilized the corresponding GIICs, and the intercalation compounds were highly thermally reduced, exhibiting no chemical interlayer functionalization of the TRG. N-methyl-N,N,N-tris(2hydroxyethyl)ammonium iodide, 1, survived annealing at high temperatures in the TRG interlayer, allowing the IL to heal defects through possible hydride transfers from the IL into the defects (absence of $\mathrm{CO}_{2}$ production) with no covalent functionalization until an annealing temperature of $200{ }^{\circ} \mathrm{C}$ was reached. The iodide-containing IL also facilitated an efficient oxygen removal from GO, as determined by both infrared absorbance and differential spectra. Conversely, ILs bearing methyl sulfate anions exhibited enhanced chemical reactivity with the GO surface, leading to functionalization of TRG. While the anion structure influenced the chemical reactions occurring within the GO interlayer region, the thermal stability of the GIICs was influenced primarily by the cation portion of the IL. For instance, cations bearing long alkyl chains did not interact with the TRG (i.e., no functionalization occurred during annealing), even when coupled with methyl sulfate anions. GIICs containing this heavily alkylated IL also exhibited an enhanced degree of thermal expansion. A significant alteration of the $T_{d}$ of both GO and GIIC also brought to our attention the role of the solvent used to prepare the composites. A dramatic decrease in the $T_{d}$ of GO in the presence PC for all three GIICs confirmed that PC enhanced the degree of oxygen removal from the GO surface.

This type of fundamental study should help guide the scientific community toward the optimal choice of a suitable IL for graphene-based systems in energy storage applications. Importantly, we have shown that the carbon-IL interactions are often very specific to the chemical environments created by the two components, and thus an a priori selection of an IL to match a carbon material may not be possible. As we have shown herein, highly functionalized ILs, such as the hydroxylated species employed (1 and 2), interact strongly with carbon materials such as GO and TRG, while sparsely functionalized ILs (e.g., 3) do not. Moreover, both the cation and anion moieties of the IL can play a role in these interactions. Suitable choices for ultracapacitor applications can be made, although the promise of commercially applicable, high performance energy storage devices incorporating ILs as electrolytes may yet be realized.

\section{CONCLUSIONS}

This overview of the effects of solvents and other molecules in GO upon thermal processing, an intrinsic component of all fabrication, highlights of complex chemical transformations, and therefore the importance of in-situ characterization to determine the mechanisms, taking place during processing for a host of applications. In addition to the techniques presented here, Raman spectroscopy provides critical complementary information, such as the concentration and quality of graphene-like material during thermal reduction. NMR spectroscopy has also been very instrumental to determine the local chemical environment of RGO. Finally, the correlation of all these spectroscopic results with the relevant properties, such as electrical conduction, electrochemical activity, and charge storage, will provide the proper feedback for device optimization.

\section{REFERENCES}

(1) Park, S.; Ruoff, R. S. Nature Nanotechnology 2009, 4, 217.

(2) Robinson, J. T.; Perkins, F. K.; Snow, E. S.; Wei, Z. Q.; Sheehan, P. E. Nano Letters 2008, 8, 3137.

(3) Stoller, M. D.; Park, S. J.; Zhu, Y. W.; An, J. H.; Ruoff, R. S. Nano Letters 2008, 8, 3498. 
(4) Brodie, B. C. Philosophical Transactions of the Royal Society of London 1859, 149, 249.

(5) Hummers, W. S.; Offeman, R. E. Journal of the American Chemical Society 1958, 80, 1339.

(6) Staudenmaier, L. Berichte der deutschen chemischen Gesellschaft 1898, 31, 1481.

(7) Scholz, W.; Boehm, H. P. Zeitschrift für anorganische und allgemeine Chemie 1969, 369, 327.

(8) Fan, X. B.; Peng, W. C.; Li, Y.; Li, X. Y.; Wang, S. L.; Zhang, G. L.; Zhang, F. B. Advanced Materials 2008, 20, 4490 .

(9) Hirata, M.; Gotou, T.; Horiuchi, S.; Fujiwara, M.; Ohba, M. Carbon 2004, 42, 2929.

(10) Stankovich, S.; Dikin, D. A.; Piner, R. D.; Kohlhaas, K. A.; Kleinhammes, A.; Jia, Y.; Wu, Y.; Nguyen, S. T.; Ruoff, R. S. Carbon 2007, 45, 1558.

(11) Szabo, T.; Berkesi, O.; Forgo, P.; Josepovits, K.; Sanakis, Y.; Petridis, D.; Dekany, I. Chemistry of Materials 2006, 18, 2740.

(12) Acik, M.; Lee, G.; Mattevi, C.; Pirkle, A.; Wallace, R. M.; Chhowalla, M.; Cho, K.; Chabal, Y. Journal of Physical Chemistry C 2011, 115, 19761.

(13) Mattevi, C.; Eda, G.; Agnoli, S.; Miller, S.; Mkhoyan, K. A.; Celik, O.; Mostrogiovanni, D.; Granozzi, G.; Garfunkel, E.; Chhowalla, M. Advanced Functional Materials 2009, 19, 2577.

(14) Eda, G.; Fanchini, G.; Chhowalla, M. Nature Nanotechnology 2008, 3, 270.

(15) Becerril, H. A.; Mao, J.; Liu, Z.; Stoltenberg, R. M.; Bao, Z.; Chen, Y. Acs Nano 2008, 2, 463.

(16) Tung, V. C.; Allen, M. J.; Yang, Y.; Kaner, R. B. Nature Nanotechnology 2009, 4, 25.

(17) Gao, X. F.; Jang, J.; Nagase, S. Journal of Physical Chemistry C 2010, 114, 832.

(18) Jung, I.; Field, D. A.; Clark, N. J.; Zhu, Y. W.; Yang, D. X.; Piner, R. D.; Stankovich, S.; Dikin, D. A.; Geisler, H.; Ventrice, C. A.; Ruoff, R. S. Journal of Physical Chemistry C 2009, 113, 18480.

(19) Liang, M. H.; Luo, B.; Zhi, L. J. International Journal of Energy Research 2009, 33, 1161.

(20) Wilson, N. R.; Pandey, P. A.; Beanland, R.; Young, R. J.; Kinloch, I. A.; Gong, L.; Liu, Z.; Suenaga, K.; Rourke, J. P.; York, S. J.; Sloan, J. Acs Nano 2009, 3, 2547.

(21) Park, S.; Lee, K. S.; Bozoklu, G.; Cai, W.; Nguyen, S. T.; Ruoff', R. S. Acs Nano 2008, 2, 572.

(22) Buchsteiner, A.; Lerf, A.; Pieper, J. Journal of Physical Chemistry B 2006, 110, 22328.

(23) Mkhoyan, K. A.; Contryman, A. W.; Silcox, J.; Stewart, D. A.; Eda, G.; Mattevi, C.; Miller, S.; Chhowalla, M. Nano Letters 2009, 9, 1058.

(24) Yu, D. S.; Dai, L. M. Journal of Physical Chemistry Letters 2010, 1, 467.

(25) Cassagneau, T.; Fendler, J. H. Advanced Materials 1998, 10, 877.

(26) Park, S.; An, J.; Suk, J. W.; Ruoff, R. S. Small 2010, 6, 210.

(27) Bunch, J. S.; van der Zande, A. M.; Verbridge, S. S.; Frank, I. W.; Tanenbaum, D. M.; Parpia, J. M.; Craighead, H. G.; McEuen, P. L. Science 2007, 315, 490.

(28) Chen, C. Y.; Rosenblatt, S.; Bolotin, K. I.; Kalb, W.; Kim, P.; Kymissis, I.; Stormer, H. L.; Heinz, T. F.; Hone, J. Nature Nanotechnology 2009, 4, 861.

(29) Dikin, D. A.; Stankovich, S.; Zimney, E. J.; Piner, R. D.; Dommett, G. H. B.; Evmenenko, G.; Nguyen, S. T.; Ruoff, R. S. Nature 2007, 448, 457.

(30) Kim, S. Y.; Park, H. S. Nano Letters 2009, 9, 969.

(31) Wang, Y.; Shi, Z. Q.; Huang, Y.; Ma, Y. F.; Wang, C. Y.; Chen, M. M.; Chen, Y. S. Journal of Physical Chemistry C 2009, 113, 13103.

(32) Medhekar, N. V.; Ramasubramaniam, A.; Ruoff, R. S.; Shenoy, V. B. Acs Nano 2010, 4, 2300.

(33) Simon, P.; Gogotsi, Y. Nature Materials 2008, 7, 845.

(34) Peter Wasserscheid, T. W. Ionic Liquids in Synthesis; Wiley-VCH Verlag GmbH and Co. KGaA, 2008.

(35) Restolho, J.; Mata, J. L.; Saramago, B. Journal of Colloid and Interface Science 2009, 340, 82.

(36) Jeong, H. K.; Colakerol, L.; Jin, M. H.; Glans, P. A.; Smith, K. E.; Lee, Y. H. Chemical Physics Letters 2008, 460, 499.

(37) Acik, M.; Mattevi, C.; Gong, C.; Lee, G.; Cho, K.; Chhowalla, M.; Chabal, Y. J. Acs Nano 2010, 4, 5861.

(38) Lerf, A.; He, H. Y.; Forster, M.; Klinowski, J. Journal of Physical Chemistry B 1998, 102, 4477.

(39) Peckett, J. W.; Trens, P.; Gougeon, R. D.; Poppl, A.; Harris, R. K.; Hudson, M. J. Carbon 2000, 38, 345. 
(40) Acik, M.; Guzman, R.; Chabal, Y. J. In Materials Research Society Symposium Proceedings 2010; Vol. $1205, \mathrm{p} 7$.

(41) Bagri, A.; Mattevi, C.; Acik, M.; Chabal, Y. J.; Chhowalla, M.; Shenoy, V. B. Nature Chemistry 2010, 2 , 581.

(42) Gomez-Navarro, C.; Meyer, J. C.; Sundaram, R. S.; Chuvilin, A.; Kurasch, S.; Burghard, M.; Kern, K.; Kaiser, U. Nano Letters 2010, 10, 1144.

(43) Radovic, L. R. Journal of the American Chemical Society 2009, 131, 17166.

(44) Li, J. L.; Kudin, K. N.; McAllister, M. J.; Prud'homme, R. K.; Aksay, I. A.; Car, R. Physical Review Letters 2006, 96.

(45) Bourlinos, A. B.; Gournis, D.; Petridis, D.; Szabo, T.; Szeri, A.; Dekany, I. Langmuir 2003, 19, 6050.

(46) Taylor, R. C.R. Chimie 2006, 9, 982.

(47) Xu, Z. P.; Xue, K. Nanotechnology 2010, 21.

(48) Gong, C.; Acik, M.; Abolfath, R. M.; Chabal, Y.; Cho, K. Journal of Physical Chemistry C 2012, 116, 9969.

(49) Acik, M.; Dreyer, D. R.; Bielawski, C. W.; Chabal, Y. J. Journal of Physical Chemistry C 2012, 116, 7867. 